\title{
Sleeping Habits and Perception of Its Health Effects among College Students
}

\author{
Rachel C. Adriansen ${ }^{1}$, Amy Childers ${ }^{2}$, Tessa Yoder ${ }^{3} \&$ Sam Abraham $^{4}$ \\ ${ }^{1}$ Traveling Cardiac Nurse, Good Samaritan Hospital, Dayton, Ohio, USA \\ ${ }^{2}$ Medical ICU, Parkview Regional Medical Center, Fort Wayne, Indiana, USA \\ ${ }^{3}$ Cardiovascular Unit, University of Toledo Medical Center, Toledo, Ohio, USA \\ ${ }^{4}$ Assistant Professor of Nursing, Bethel College, Indiana, USA \\ Correspondence: Sam Abraham, Assistant Professor of Nursing, Bethel College, Indiana, 46545, USA.
}

Received: October 8, 2017

Accepted: October 29, 2017

Online Published: November 1, 2017

doi:10.20849/ijsn.v2i2.206

URL: https://doi.org/10.20849/ijsn.v2i2.206

\begin{abstract}
Inadequate sleep has detrimental effects on both students' health and academic performance. While college students may know this information, they often do not prioritize sleep above other responsibilities of college life nor perceive their own health as being threatened. The purpose of this quantitative, descriptive study was to determine the sleeping habits and perception of its health effects among college students. In this study, 116 college students in the Midwestern United States were surveyed. Participants completed a demographic and a 19-item Likert-type survey about their sleep habits and their perception of its health effects. In this study, $61 \%$ of participants reported obtaining at least an average of 7 hours of sleep per night. In addition, $77 \%$ of the participants reported taking naps during the day, with $51 \%$ of the naps lasting at least an hour. By comparing the participants' sleeping habits with the review of the literature, it was concluded that overall, participants did not have beneficial sleeping habits. The majority of the participants $(\mathrm{M}=3.49 ; \mathrm{SD}=0.57$ on a 4- point Likert-type scale), agreed that academics are affected because of the lack of sleep. In conclusion, college students do not have beneficial sleeping habits.
\end{abstract}

Keywords: sleep habits, college students sleep habits, sleep and health

\section{Introduction}

National Sleep Foundation (2017) report indicates, "50 to 70 million Americans are affected by sleep problems that can diminish health, alertness and safety" (para 1). Inadequate sleep is a common problem among college students (Todd \& Mullan, 2014). Many students report that they are sleep deprived (Huang, Yang, Wu, Liu, \& Chen, 2014). In addition, "25-50\% of students report significant daytime sleepiness" (Huang et al., 2014, p. 1049). Adequate sleep is fundamental to health because it affects many aspects of one's "emotional, cognitive, and psychomotor abilities" (Orzech, Salafsky, \& Hamilton, 2011, p. 612).

A study reported in CNN (Knight, 2017) indicated, students' grades could be linked to their sleep schedules. In another cross-sectional study, Faris et al. (2016) found that energy drink consumption is associated with reduced sleep quality among college students. Orzech et al. (2011) asserted that alterations in college students' sleep can be also attributed to late bedtimes, irregular sleep schedules, an increased number of social events, and heavy academic load. Nutrition, lack of exercise, social lives, and technology are also factors that can decrease the quality of college students' sleep. Lack of sleep can lead to social strain, emotional instability, and health problems, which can affect students in many negative ways. It is important to understand why students may neglect sleep and how to teach them the importance of sleep so that they will have better health and wellbeing (Orzech et al., 2011).

Adequate sleep is an important precursor to health, but college students are notorious for receiving an inadequate amount of sleep. Orzech et al. (2011) affirmed poor sleep habits of college students "contributes to decreased cognitive, psychomotor, and emotional functioning" (p. 612). College students may know this information, but often do not prioritize adequate sleep above other responsibilities of college life nor perceive their own health as being threatened. The purpose of this quantitative, descriptive study was to determine the sleeping habits and perception of its health effects of college students. Research questions (RQ) included 1) What are the sleeping 
habits of college students? 2) Do college students perceive that their health habits affect their sleep?

\section{Review of the Literature}

The review of the literature contains studies obtained from the Cumulative Index to National and Allied Health Literature (CINAHL) database and Medline with Full Text. Keywords used to find the articles included sleeping habits, health effects of sleep, sleep and college students, sleep behaviors, and sleep hygiene. The peer-reviewed studies referenced in this study were published from 2010 to 2017. All studies are about college students' sleep and health. More specifically, the studies show the relationship of sleep with college students' perceptions, sleep hygiene, daytime sleepiness, nutrition, and exercise.

\subsection{College Students' Perception of Health Effects of Sleep}

College students attribute their poor sleep to anxiety, stress, and conflicting social and work demands. The "stress associated with balancing multiple responsibilities" is the principal reason given by college students for inadequate sleep (Knowlden \& Sharma, 2014, p. 276).

College students' perceptions of the causes and effects of their poor sleep determine whether they take action to improve their sleep. Knowlden and Sharma used the health belief model in their study at the University of Alabama to assess students' sleep perceptions and to recommend interventions to improve sleep.

Knowlden and Sharma (2014) surveyed 188 students about their health beliefs related to sleep behaviors. The researchers asked questions that evaluated the students' perceived susceptibility, perceived severity, perceived benefits, perceived barriers, self-efficacy, sleep behavior, and cues to action for adequate sleep. The study indicated that the short-term consequences of stress and concentration were the main motivators for students to improve their sleep, rather than the long-term consequences of morbidity and mortality. Other cues that motivated college students to obtain an adequate sleep were physical and mental fatigue. Additionally, self-efficacy for adequate sleep led to more sleep. Self-efficacy behaviors for adequate sleep include "a bedroom environment conducive to adequate sleep, ability to reduce mental and physical stressors, and maintenance of a consistent sleep schedule" (Knowlden \& Sharma, 2014, p. 276). Therefore, short-term consequences, physical and mental fatigue, and self-efficacy behaviors were identified as the key motivators for college students to improve their sleep behaviors.

\subsection{College Students'Sleeping Habits}

\subsubsection{Sleep Hygiene}

Attaining adequate sleep is multi-faceted. While many aspects of sleep are non-modifiable, an aspect that is modifiable is sleep hygiene. By increasing sleep hygiene behaviors, college students can improve their sleep. Multiple studies evaluate factors that contribute to increased sleep hygiene.

Primarily, Todd and Mullan (2013) considered executive function as a trait leading to increased sleep hygiene behaviors and thus improved sleep. The executive function "covers a broad range of higher order functions that are involved in goal-directed behavior, to both plan and work towards goals as well as maintaining flexibility when unexpected situations arise" (Todd \& Mullan, 2013, p. 277). In this study, 190 University of Sydney students were evaluated with five tools assessing executive function. They found that cognitive flexibility is central to sleep hygiene. Hence, through training and manipulating cognitive flexibility, university students were able to improve their sleep.

In a later study, Todd and Mullan (2014) suggested self-monitoring behavior as a factor that increased sleep hygiene behaviors. They studied the University of Sydney students to determine if self-monitoring interventions, such as keeping a sleep diary, would improve sleep hygiene behaviors. Sleep hygiene behaviors consist of avoiding activities that stimulate stress and anxiety before bed, making the bedroom environment conductive to sleep, and reducing hunger as well as thirst before going to bed. The sleep diary intervention increased the frequency that students performed one of the sleep hygiene behaviors - avoiding activities at bedtime that stimulated stress and anxiety. They found a significant difference between the control and experimental groups for that behavior. Furthermore, Todd and Mullan mentioned other self-monitoring interventions that were found to be successful at improving sleep hygiene behaviors, including reducing alcohol and tobacco, consuming a balanced diet, and regularly exercising. Overall, self-monitoring contributed to increased sleep hygiene behaviors and thus improved sleep (Todd \& Mullan, 2014).

\subsubsection{Sleep Habits}

Although most college students know sleep is important, many do not prioritize sleep, and others report symptoms of sleep depravity. These symptoms include daytime sleepiness, decreased mental abilities, and 
decreased physical abilities. Identifying why students have poor sleep quality determines how this can be avoided (Orzech et al., 2011).

Daytime sleepiness has become a problem for students. Low academic performance can be a serious consequence of daytime sleepiness, either from falling asleep in class or lack of concentration while studying. It is estimated that as high as $50 \%$ of college students have symptoms of daytime sleepiness (Orzech et al., 2011). Huang et al. (2014) conducted a cross-sectional, quantitative survey of 93 female nursing students to investigate daytime sleepiness and its effects. By using questionnaires and the Epworth Sleepiness Scale, the Pittsburgh Sleep Quality Index, and the Perceived Symptom Scale, the students rated their sleepiness and functioning during the day. The data indicated that $35 \%$ of students had experienced excessive daytime sleepiness, and $33 \%$ to $50 \%$ admitted to falling asleep during the day. Huang et al. found that sleep disturbances, club participation, sleep latency, poor sleep quality, perceived symptoms, and daytime dysfunction were reasons students struggled with daytime sleepiness. Learning the significance of sleep quality and how sleep quality affects academic performance, mood, and stress levels may encourage students to take more responsibility for their sleep habits.

Likewise, Orzech et al. (2011) found similar results in their study. The study was completed both quantitatively and qualitatively from October 2005 through April 2007. The sample size included 4,513 students. The results indicated that many students struggle with getting enough sleep, which decreases the students' overall health and wellbeing. When the students' sleep quality increased, their grade point average, memory, and concentration increased, as well as their energy and overall well-being. The research confirmed that decreased sleep quality was associated with poor mental health and academic performance. College students who had anxiety and depression because of academic challenges had poor sleep quality. Students reported that when they had a lack of sleep, it caused more inter-relational conflict with others, including family, roommates, significant others, and friends. After the survey, the students learned through posters, advertisements, and reading materials as to how to improve their sleep and the benefits of sleep. From this education, 971 students improved their sleep quality, which illustrates the significance of teaching students about the importance of good sleep hygiene (Orzech et al., 2011).

\subsubsection{Nutritional Habits}

Research has also shown an effect on nutritional intake and the quality of sleep a person obtains. Lindseth, Lindseth, and Thompson (2013) sampled 44 healthy adults in a double-blind, quantitative study. The purpose of this study was to determine if macronutrients found in food affect sleep. The macronutrients included were protein, fat, and carbohydrates. Demographic questions, food intake, sleep actigraphy measures (Actigraphy is a non-invasive method of monitoring rest/activity cycles in humans) and the Pittsburgh Sleep Quality Index were assessed during this study (Lindseth at al., 2013).

Lindseth et al. (2013) indicated that people who had a high-carbohydrate diet had an overall lower mean for sleep latency. In other words, participants who had a high-carbohydrate diet were able to fall asleep quicker than those who did not. High caloric intake was also shown to provide better sleep efficiency. Another area that had statistical relevance was that participants who consumed a high-protein diet reported fewer times that they awoke throughout the night (Lindseth et al., 2013).

Likewise, Calvin et al. (2013) found a relationship between nutritional intake and sleep. Their quantitative study sampled 17 participants. The purpose of their study was to determine if sleep restriction would increase caloric intake while reducing activity expenditure. The study hypothesized that leptin (a protein produced by fatty tissue believed to regulate body fat storage) would decrease, and ghrelin (an enzyme produced by stomach lining cells that stimulate appetite) would increase with sleep restriction. The study showed no relationship between leptin and ghrelin. Similarly, physical activity did not change between the experimental group and the control group. However, the participants who were deprived of sleep consumed 677 more calories than the control group. These findings indicated a relationship between sleep deprivation and increased caloric intake (Calvin et al., 2013).

Ho and Chung (2013) studied college students to examine if drinking caffeinated beverages in the evening could improve sleep quality. Ten students were selected for a 14-day experiment in this quantitative study. For the first week, the students drank caffeinated beverages, and then the next week, the group was divided into caffeinated-beverage-drinkers and decaffeinated-beverage-drinkers. Next, their sleep quality was examined through the Pittsburg Sleep Quality Index, a sleep log, and a wrist actigraph (to detect sleep-wake patterns). The results showed no significant differences between the groups, suggesting that caffeine was not helpful in sleep promotion (Ho \& Chung, 2013).

In conclusion, the relationship between sleep quality and nutritional intake is relevant. Further study would need to be conducted to determine if sleep quality affects nutritional intake or vice versa. However, these studies 
indicated that participants slept better when consuming a proper nutritional diet. Therefore, students who obtain the adequate amount of sleep per night are more likely to eat healthier and maintain a healthy lifestyle compared to those who do not.

\subsubsection{Exercise Habits}

Another area of college students' lives that may affect their quality of sleep is exercise. Gerber, Brand, Holsboer-Trachsler, and Pühse (2010) evaluated the relationship between exercise and sleep. The quantitative study included a sample size of 862 students from Switzerland. The purpose of the study was to determine "if a person's perceived physical fitness, the level of exercise, and perceived lack of physical activity were associated with insomnia, dysfunctional sleep-related thoughts, and quality of sleep among young adults" (Gerber et al., 2010, p. 894). This study assessed the quality of sleep by measuring the students' difficulty falling asleep, difficulty maintaining sleep, waking up early, sleepiness during the day, low daytime performance, low satisfaction with sleep, and worrying about sleep (Gerber et al., 2010).

Gerber et al. (2010) found that there was a high correlation between sleep disturbances and physical inactivity. This indicates that participants who had more sleep disturbances rated their levels of physical activity lower. Additionally, the researchers analyzed the data comparing males and females. The results indicated that overall, women had lower sleep quality and felt more tired when going to bed. Gerber et al. (2010) indicated, "Participants with high fitness levels and no perceived lack of physical activity exhibited lower insomnia scores, were less inclined to ruminate about unresolved problems and reported less excessive intrusive thoughts about sleep difficulties" (p. 899). Finally, students who rated their fitness higher reported that they felt more restored upon wakening in the morning. Those students also reported a reduced delay in falling asleep. Overall, Gerber et al. (2010) found a positive correlation between sleep quality and exercise. As students exercised more, their sleep quality improved.

Sleeping habits and perceptions of sleep were researched in-depth in this literature review. In summary, poor sleep habits of college students contributed to impair cognitive, psychomotor, and emotional functioning. Some of these studies support that sleep is important to college students' health and academic performance. This information may be useful in understanding how to improve sleep. These studies indicated that sleep has an important role in college students' lives and were used in determining a basis for the current study.

\section{Methodology}

To best compile evidence from a broad spectrum of students, the ideal research methodology for gathering information is a quantitative approach. A quantitative survey gave a more representative sample of college students because a variety of ages, ethnicities, and academic years were analyzed. A qualitative study, on the other hand, would have been limited in number and scope of participants.

The sample size was 116 college students. Participants were students 18 years and older. The subjects were legally and ethically capable of participating in the study. The surveys were conducted on the college campus during dinner hours. Privacy and confidentiality of participants was maintained. The institutional review board approval was obtained before the survey administration. The participants signed an informed consent before participating. The surveys were kept anonymous by excluding the name and other identifying information. To ensure confidentiality, participants submitted their completed surveys and the signed informed consent in separate, designated manila envelopes. The participants were then thanked and offered a mint candy as an appreciation for participation.

A new survey instrument was created after a thorough review of the literature (see Table 1). To obtain face-validity, the survey statements were reviewed and critiqued by two peers and two nursing faculty. Revisions were made based on the feedback. Likert-type statements 1-12 addressed RQ 1 and 13-19 addressed RQ 2. The demographic questions allowed the results to be analyzed respectively for aggregates within college students. In these ways, this survey tool better described the sleeping habits and perception of its health effects of college students.

\section{Table 1. Survey}

Demographic Characteristics:

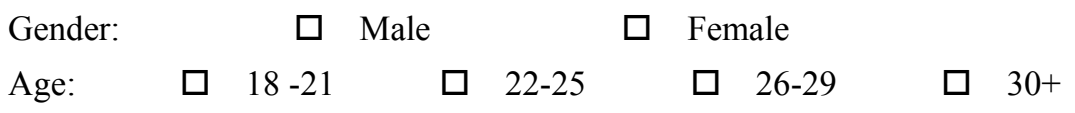

Average hours of sleep per night: $\quad \square \quad$ Less than $6 \quad \square \quad 7$ Hours $\quad \square \quad 8$ hours $\quad \square \quad 9+$ 
How many times a week do you take a nap?

What is the average length of your nap?

Year in school:

$\square \quad 1$

$\square \quad 2$

$2 \square 3$

4

$\square 5+$

\section{Ethnicity: $\quad \square$ White $\quad \square$ Other}

This survey is designed to determine the sleeping habits and perceptions of college students. Please select one of the four selections for each statement.

\begin{tabular}{|c|c|c|c|c|c|}
\hline & Sleeping Habits & Never 1 & Rarely 2 & Often 3 & Always 4 \\
\hline 1 & It takes more than 30 minutes for me to fall asleep. & $\mathrm{N}$ & $\mathrm{R}$ & $\mathrm{O}$ & $\mathrm{A}$ \\
\hline 2 & $\begin{array}{l}\text { During the first } 30 \text { minutes of waking up in the morning, I } \\
\text { usually feel groggy. }\end{array}$ & $\mathrm{N}$ & $\mathrm{R}$ & $\mathrm{O}$ & $\mathrm{A}$ \\
\hline 3 & $\begin{array}{l}\text { During the first } 30 \text { minutes after waking up in the morning, I } \\
\text { usually feel alert. }\end{array}$ & $\mathrm{N}$ & $\mathrm{R}$ & $\mathrm{O}$ & A \\
\hline 4 & My sleep environment is relaxing. & $\mathrm{N}$ & $\mathrm{R}$ & $\mathrm{O}$ & A \\
\hline 5 & I go to bed at a consistent time throughout the week. & $\mathrm{N}$ & $\mathrm{R}$ & $\mathrm{O}$ & $\mathrm{A}$ \\
\hline 6 & I have been told that I snore when I am asleep. & $\mathrm{N}$ & $\mathrm{R}$ & $\mathrm{O}$ & $\mathrm{A}$ \\
\hline 7 & $\begin{array}{l}\text { I use an electronic device when lying in bed to go to sleep } \\
\text { (examples: phone, } T V, \text { iPad...) }\end{array}$ & $\mathrm{N}$ & $\mathrm{R}$ & $\mathrm{O}$ & $\mathrm{A}$ \\
\hline 8 & I wake up from sleep three or more times every night & $\mathrm{N}$ & $\mathrm{R}$ & $\mathrm{O}$ & A \\
\hline 9 & $\begin{array}{l}\text { I have to get up in the middle of the night to use the } \\
\text { restroom. }\end{array}$ & $\mathrm{N}$ & $\mathrm{R}$ & $\mathrm{O}$ & $\mathrm{A}$ \\
\hline 10 & $\begin{array}{l}\text { When I wake up during the night, I have trouble going back } \\
\text { to sleep. }\end{array}$ & $\mathrm{N}$ & $\mathrm{R}$ & $\mathrm{O}$ & $\mathrm{A}$ \\
\hline 11 & I have to take medications to go to sleep. & $\mathrm{N}$ & $\mathrm{R}$ & $\mathrm{O}$ & $\mathrm{A}$ \\
\hline \multirow[t]{2}{*}{12} & I feel that the quality of my sleep is unsatisfactory. & $\mathrm{N}$ & $\mathrm{R}$ & $\mathrm{O}$ & $\mathrm{A}$ \\
\hline & Perception of Sleeping Habits & $\begin{array}{l}\text { Strongly } \\
\text { Disagree } 1\end{array}$ & $\begin{array}{l}\text { Disagree } \\
2\end{array}$ & Agree 3 & $\begin{array}{l}\text { Strongly } \\
\text { Agree } 4\end{array}$ \\
\hline 13 & Caffeinated drinks keep people awake at night. & SD & $\mathrm{D}$ & $\mathrm{A}$ & SA \\
\hline 14 & Exercise helps people sleep better. & SD & $\mathrm{D}$ & $\mathrm{A}$ & SA \\
\hline 15 & Academics are affected because of lack of sleep. & SD & $\mathrm{D}$ & $\mathrm{A}$ & SA \\
\hline 16 & Lack of sleep makes an individual emotionally unstable. & SD & $\mathrm{D}$ & A & SA \\
\hline 17 & Socially active people do not get enough sleep. & SD & $\mathrm{D}$ & $\mathrm{A}$ & SA \\
\hline 18 & $\begin{array}{l}\text { To be healthy, an individual needs at least } 8 \text { hours of sleep } \\
\text { per night. }\end{array}$ & SD & $\mathrm{D}$ & $\mathrm{A}$ & SA \\
\hline 19 & $\begin{array}{l}\text { Eating high-fat foods for dinner causes a disturbance in } \\
\text { sleep pattern. }\end{array}$ & SD & $\mathrm{D}$ & A & SA \\
\hline
\end{tabular}

\section{Results}

The purpose of this quantitative study was to determine the sleeping habits and perception of its health effects of college students. To obtain the best representation for the data analysis, the quantitative measures of percentage distribution, mean calculation, and standard deviation were used. Results for RQ 1: What are the sleeping habits of college students? and RQ 2: Do college students perceive that their health habits affect their sleep? are described below.

Table 1 displays the demographic characteristics of the 116 participants. There were more females $(65 \%)$ than 
males (35\%). All of the participants were between ages 18 and 25, with the majority being between ages 18 and $21(78 \%)$. More than half of participants reported receiving an average of seven hours of sleep per night (61\%). Only $16 \%$ of participants reported receiving six or fewer hours of sleep per night, and only $23 \%$ of participants reported receiving eight or more hours of sleep per night. The majority of participants were of white ethnicity $(87 \%)$.

The survey contained two qualitative questions within the demographic characteristic section. These questions pertained to number and duration of naps per week. The results showed that the majority of students took naps (77\%). Of those students, 44\% took one to two naps per week, while 33\% took three or more naps per week. More than half $(54 \%)$ of the students reported taking naps of at least an hour each time.

Table 2. Descriptive statistics for participant demographics and background

\begin{tabular}{llc}
\hline Variable & f & $\%$ \\
\hline
\end{tabular}

Gender:

Male

Female

Age:

Average Hours of Sleep Per Night:

$\leq 6$ Hours

7 Hours

8 Hours

$\geq 9$ Hours

Year in School

Ethnicity:

White

Other

Note $(\mathrm{N}=116)$ 


\subsection{Sleeping Habits}

The responses to the RQ 1, What are the sleeping habits of college students? are shown in Table 3. The sleeping habits targeted include sleep environment, bedtime, the length of sleep, the amount of time required to fall asleep, use of technology in bed, frequency of waking up throughout the night, and energy through the day. The top three most agreed-upon sleeping habits of college students were having a relaxing sleep environment $(M=3.03$, $\mathrm{SD}=0.76$ ), feeling groggy within 30 minutes of waking up $(\mathrm{M}=2.74, \mathrm{SD}=0.76)$, and using an electronic device while lying in bed to go to sleep $(2.60, \mathrm{SD}=1.12)$. The participants had weakest levels of agreement with the sleeping habits of snoring $(\mathrm{M}=1.56, \mathrm{SD}=0.80)$ and taking medications to go to sleep $(\mathrm{M}=1.24, \mathrm{SD}=0.50)$.

Table 3. Sleeping habits of college students

\begin{tabular}{lll}
\hline Variable & M & SD \\
\hline My sleep environment is relaxing. & 3.03 & 0.76 \\
During the first 30 minutes of waking up in the morning, I usually feel groggy. & 2.74 & 0.76 \\
I use an electronic device when lying in bed to go to sleep (examples: phone, & 2.60 & 1.12 \\
TV, iPad...) & & 0.77 \\
I go to bed at a consistent time throughout the week. & 2.57 & 0.91 \\
It takes me more than 30 minutes for me to fall asleep. & 2.42 & 0.70 \\
I feel that the quality of my sleep is unsatisfactory. & 2.34 & 0.60 \\
During the first 30 minutes of waking up in the morning, I usually feel alert. & 2.26 & 0.78 \\
When I wake up during the night, I have trouble going back to sleep. & 2.07 & 0.80 \\
I wake up from sleep three or more times every night. & 1.93 & 0.80 \\
I have to get up in the middle of the night to use the restroom. & 1.78 & 1.56 \\
I have been told that I snore when I am asleep. & 1.24 & 0.80 \\
I have to take medications to go to sleep. & & 0.50
\end{tabular}

Note. ( $\mathrm{N}=116)$. On a 4-point Likert-type scale of never (1) to always (4).

\subsection{Perceptions of Sleep on Health}

RQ 2 (see Table 4) was, "Do college students perceive that their health habits affect their sleep?" Participants were asked if they perceived a relationship between sleep and caffeine, exercise, nutrition, academics, and social relationships. The items with which the participants agreed most strongly were: academics are affected because of lack of sleep $(\mathrm{M}=3.49, \mathrm{SD}=0.57)$, exercise helps people sleep better $(\mathrm{M}=3.30, \mathrm{SD}=0.58)$, and lack of sleep makes an individual emotionally unstable $(\mathrm{M}=3.28, \mathrm{SD}=0.58)$. The item with which the participants disagreed most strongly was eating high-fat foods for dinner causes a disturbance in sleep pattern $(\mathrm{M}=2.58, \mathrm{SD}=0.67)$. 
Table 4. Perception on sleep affecting health

\begin{tabular}{lll}
\hline Variable & Mean & SD \\
\hline Academics are affected because of lack of sleep. & 3.49 & 0.57 \\
Exercise helps people sleep better. & 3.30 & 0.58 \\
Lack of sleep makes an individual emotionally unstable. & 3.28 & 0.58 \\
Caffeinated drinks keep people awake at night. & 2.89 & 0.72 \\
To be healthy, an individual needs at least 8 hours of sleep per night. & 2.79 & 0.65 \\
Socially active people do not get enough sleep. & & 0.60 \\
Eating high-fat foods for dinner causes a disturbance in sleep pattern. & 2.78 & 0.67
\end{tabular}

Note. $(\mathrm{N}=116)$ On a 4-point Likert-type scale of agreement, strongly disagree (1) to strongly agree (4).k

\section{Discussion}

In this study, the sleeping habits and perception of its health effects of college students were investigated. Participants mostly agreed on the sleeping habit of a relaxing sleep environment. Todd and Mullan (2014) found that creating a peaceful sleep environment improved college students' sleep. Thus, creating a peaceful sleep environment is a healthful, sleep-promoting behavior. One trend that was not found in the literature was the effects of longer naps on sleeping habits. The participants claimed that $54 \%$ of them took at least an hour-long nap. Further research could be obtained on the effects of longer naps on sleeping habits. Most participants of the current study agreed with the perception that academics are affected by the lack of sleep. This perception is supported by the literature (Orzech et al., 2011), as sleep quality is positively correlated with increased grade point average, memory, and concentration. The next perception with which participants strongly agreed was that lack of sleep makes people emotionally unstable. Likewise, it can be concluded from the literature that lack of sleep causes inter-relational conflicts (Orzech et al., 2011). Another perception that participants strongly agreed with was that exercise improves sleep. Similarly, Gerber et al. (2010) reported that sleep quality is positively correlated with exercise. The lowest agreement, which did not match with the literature was "eating high-fat foods at dinner disturbs sleep." However, Lindseth et al. (2013) found that students sleep better when they consume a proper nutritional diet. In conclusion, the statistics in the current study strengthens the hypothesis that college students do not have beneficial sleeping habits.

\section{Limitations}

With any research project, certain limitations exist. This study included students enrolled in one college. A convenience sample was used; therefore, the number of students who agreed to participate could be a limitation. The participants were $87 \%$ Caucasian making this study homogenous and thus a limitation. Even though the survey instrument was developed after a thorough review of the literature, the tool was new, which could add to the limitation. Face validity was obtained; however, reliability could not be guaranteed because it was not tested in other studies.

\section{Conclusions}

By comparing the participants' sleeping habits with the review of the literature, it can be concluded that overall, participants did not have beneficial sleeping habits. The strongest sleeping habits were having a relaxing sleeping environment, feeling groggy when waking up in the morning, and falling to sleep with an electronic device. The strongest perceptions were that sleep affects academic, social lives, and emotional stability, all of which were supported by the review of the literature. The weakest perception was that college students did not perceive eating healthy as one way to obtain adequate sleep. Increasing college students' knowledge about the importance of rest and sleep can benefit them academically, emotionally, and physically. It is recommended that further research is completed on the specific correlation between lack of sleep and its effect on an individual's emotional, academic, and physical performance. Lastly, it is recommended to research the effects of both taking 
a nap during the day and using electronics to fall asleep on sleep quality.

\section{Acknowledgment}

The authors wish to acknowledge Dr. Deborah Gillum, the Dean of Nursing, Bethel College, Indiana, for offering valuable comments during the early stages of the study. We also like to thank Bethel College administrators for giving us the opportunity to conduct this study.

\section{Permission to use the Survey Tool}

S. Abraham, RN, MS, DHA, School of Nursing, Bethel College, Indiana. samuel.abraham@bethelcollege.edu The new survey instrument is included in this study. Validity and reliability has not been established. This tool is free to use with attribute. You may modify to suit your study.

\section{References}

Calvin, A., Carter, R., Adachi, T., G Macedo, P., Albuquerque, F., van der Walt, C., \& Somers, V. (2013). Effects of experimental sleep restriction on caloric intake and activity energy expenditure. Chest, 144(1), 79-86. https://doi.org/10.1378/chest.12-2829

Faris, M., Jahrami, H., Al-Hilali, M., Marwa , J., Chehyber, N., Ali, S... Shaker Obaid, R. (2016). Energy drink consumption is associated with reduced sleep quality among college students: A cross-sectional study: Energy drinks affect sleep quality among college students. Nutrition \& Dietetics, 74. https://doi.org/10.1111/1747-0080.12289

Gerber, M., Brand, S., Holsboer-Trachsler, E., \& Pühse, U. (2010). Fitness and exercise as correlates of sleep complaints: Is it all in our minds? Medicine \& Science in Sports \& Exercise, 42(5), 893-901. https://doi.org/10.1249/MSS.0b013e3181c0ea8c

Ho, S. C., \& Chung, J. W. (2013). The effects of caffeine on sleep: A pilot study. Application of Nursing Research, 26(2), 80-84. https://doi.org/10.1016/j.apnr.2012.08.004

Huang, C., Yang, L., Wu, L., Liu, Y., \& Chen, H. (2014). Determinants of daytime sleepiness in first-year nursing students: A questionnaire survey. Nurse Education Today, 34(6), 1048-1053. https://doi.org/10.1016/j.nedt.2013.11.005

Knight, V. (June, 2017). Study links college students' grades to sleep schedules. CNN Health. Retrieved from http://www.cnn.com/2017/06/12/health/student-sleep-grades-study/index.html

Knowlden, A. P., \& Sharma, M. (2014). Health belief structural equation model predicting sleep behavior of employed college students. Family and Community Health, 37(4), 271-278. https://doi.org/10.1097/FCH.0000000000000043

Lindseth, G., Lindseth, P., \& Thompson, M. (2013). Nutritional effects on sleep. Western Journal of Nursing Research, 35(4), 497-513. https://doi.org/10.1177/0193945911416379

National Sleep Foundation. (2017). Sleep studies. Retrieved from https://sleepfoundation.org/sleep-topics/sleep-studies

Orzech, K. M., Salafsky, D. B., \& Hamilton, L. A. (2011). The state of sleep among college students at a large public university. Journal of American College Health, 59(7), 612-619. https://doi.org/10.1080/07448481.2010.520051

Todd, J., \& Mullan, B. (2013). The role of self-regulation in predicting sleep hygiene in university students. Psychology, Health \& Medicine, 18(3), 275-288. https://doi.org/10.1080/13548506.2012.701756

Todd, J., \& Mullan, B. (2014). The role of self-monitoring and response inhibition in improving sleep behaviors. International Journal of Behavioral Medicine, 21(3), 470-477. https://doi.org/10.1007/s12529-013-9328-8

\section{Copyrights}

Copyright for this article is retained by the author(s), with first publication rights granted to the journal.

This is an open-access article distributed under the terms and conditions of the Creative Commons Attribution license (http://creativecommons.org/licenses/by/4.0/). 